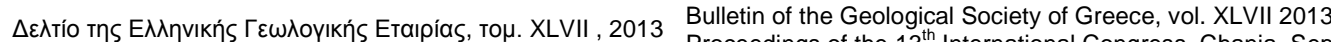
Proceedings of the $13^{\text {th }}$ International Congress, Chania, Sept.

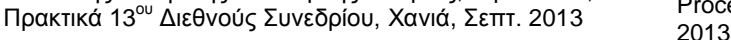

\title{
CORRELATION BETWEEN MECHANICAL AND PETROGRAPHIC PARAMETERS OF SANDSTONES
}

\author{
Ktena St. and Sabatakakis N. \\ University of Patras, Department of Geology, Section of Applied Geology and Geophysics, \\ Laboratory of Engineering Geology, 26500 Patras, Greece
}

\begin{abstract}
Sandstone intact rock specimens are tested to study their point loading strength, while the microscopic properties of the tested specimens are analyzed in thin sections to determine the mineral composition, grain size, cement and contact modes between grains. The intrinsic influence of petrographic characteristics on measured strength is evaluated using regression analysis among the obtained laboratory data. Key words: microscopic characteristics, rock strength, packing density.

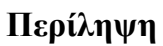

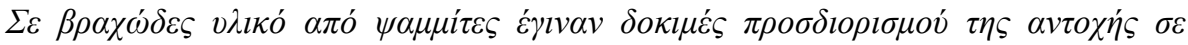

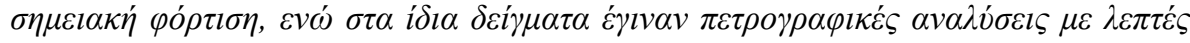

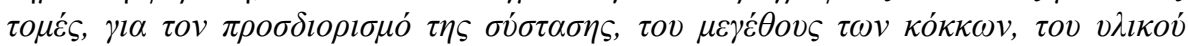

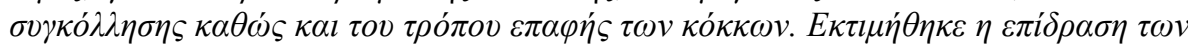

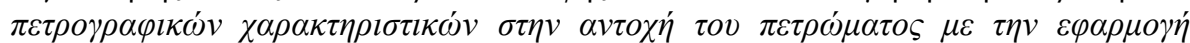

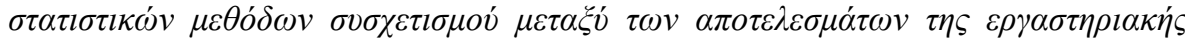
É $\rho \varepsilon v v \alpha \varsigma$.

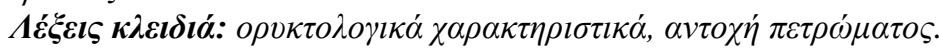

\section{Introduction}

The strength of intact rock is one of the main mechanical characteristics of rock material. Test results obtained from point loading test are indirectly applicable to the estimation of rock mass classification and behavior, while conversion factors relating point load strength and uniaxial compressive strength have been at times proposed (Bieniawski, 1974; 1975; Hawkins and Oliver, 1986; Norbury, 1986; Romana, 1999; Kahraman, 2001; Tsiambaos and Sabatakakis, 2004; Sabatakakis et al, 2008).

The petrographic characteristics of rocks have a constructive effect on the macro-mechanical properties and especially on rock strength. Mineral composition, grain size and microstructure as described by the means of petrographic indices (microscopic factors), are the most important parameters that influence the rock strength.

The influence of microscopic factors on the macroscopic strength of rock is studied with regard to the following aspects: (a) Mineralogical composition and especially the quartz content $\left(\mathrm{q}_{\mathrm{z}}\right)$, (b) Matrix - cement content (mtx) that is often referred to the fine particles between the grains and (c) Grain particle packing that can be described by parameters such as packing density (PD) and grain 
area ratio (GAR) which is defined as the ratio between the grain area and the total area in the selected range of the specimen image (Ersoy and Waller, 1995).

This study aims at investigating the influence of petrography on point load values of intact sandstone rocks tested. The examined sandstone samples have been obtained from different sites and belong to the flysch formation of Olonos - Pindos, Gavrovo and Ionia geotectonic zones which occupies a large area of western Greece. In general, the studied sandstones have a variable composition and are composed of quartz (up to 50\%), while they have a large of feldspar (up to $50 \%$ ) and up to $30 \%$ rock fragments. They can be classified as "very fine to fine sands" according to (Wentworth, 1922) grain size scale, "well to poor shorting" and "angular to rounded" based on (Pettijohn et al., 1987) classification scheme.

\section{Test Procedure}

Twenty one block samples were obtained from different outcrops of sandstones formations. Laboratory core drill and saw machines were used to cut the samples and end faces in order to provide cylindrical specimens in size, shape and ends geometries according to testing requirements. The specimen size was $54 \mathrm{~mm}(\mathrm{NX})$ in diameter. Diametrical point loading tests were carried out with the loading axis perpendicular to any visible discontinuity surface, otherwise the test was unacceptable.

The execution of point load tests on intact rock material was in accordance with I.S.R.M. suggested methods (1985).

A quantitative analysis of rock specimen petrographic characteristics was carried out on thin sections using standard polarizing microscope. The main rock - forming minerals, the percentage composition, the cement and contact modes between grains in thin sections were examined.

\section{Test Results}

In Table 1 the test results are summarized including for each parameter the range of values, the mean value and the number of specimens tested. The scattering of data is mainly due to the different degree of diagenesis (compaction or/and cementation) for the various horizons of the sandstone sediments.

Table 1 - Results of intact rock strength and microscopic factors.

\begin{tabular}{|l|c|c|c|c|c|}
\hline Results and statistical parameters & $\begin{array}{c}\mathbf{I}_{\mathbf{s}(\mathbf{5 0})} \\
\mathbf{M P a})\end{array}$ & $\begin{array}{c}\mathbf{q}_{\mathbf{z}} \\
(\mathbf{\%})\end{array}$ & $\begin{array}{c}\mathbf{m t x} \\
(\boldsymbol{\%})\end{array}$ & $\begin{array}{c}\text { GAR } \\
(\boldsymbol{\%})\end{array}$ & $\begin{array}{c}\text { PD } \\
(\boldsymbol{\%})\end{array}$ \\
\hline Minimum value (Min) & 0.42 & 10.00 & 3.00 & 11.00 & 29.70 \\
\hline Maximum value (Max) & 10.31 & 50.00 & 30.00 & 70.00 & 62.04 \\
\hline Mean value (Mean) & 5.05 & 29.18 & 16.66 & 41.88 & 50.39 \\
\hline Standard deviation (Std dev) & 3.05 & 13.18 & 8.48 & 14.46 & 8.78 \\
\hline Number of samples (N) & 21 & 17 & 19 & 17 & 16 \\
\hline
\end{tabular}

\section{Correlations Between Rock Properties}

Regression analysis was applied to define the relations among the testing data. The procedure is to fit a line through the points, which is computed so that the squared deviations of the measured points from the line are minimized. The line is defined by the relevant equation, whereas the value of coefficient of determination or R-square value is determined. The number of samples (n) used for regression analysis is also shown.

XLVII, No 3 - 1727 
- Quartz content, $\mathrm{q}_{\mathrm{z}}(\%)$ and point loading index $\mathrm{I}_{\mathrm{s}(50)}(\mathrm{MPa})$

As shown in Figure 1 the quartz content contributes positively to the point load strength of the tested sandstones and the trend relating these parameters is an approximately linear function. Positive relations with uniaxial compressive strength of sandstones have been also described by (Smart et al., 1982), (Shakoor and Bonelli, 1991), (Zorlu et al., 2004). Nevertheless, there are situations that the quartz content of sandstones has no effect on their strength (Bell, 1978; Dobereiner and De Freitas, 1986; Ulusey et al., 1994).

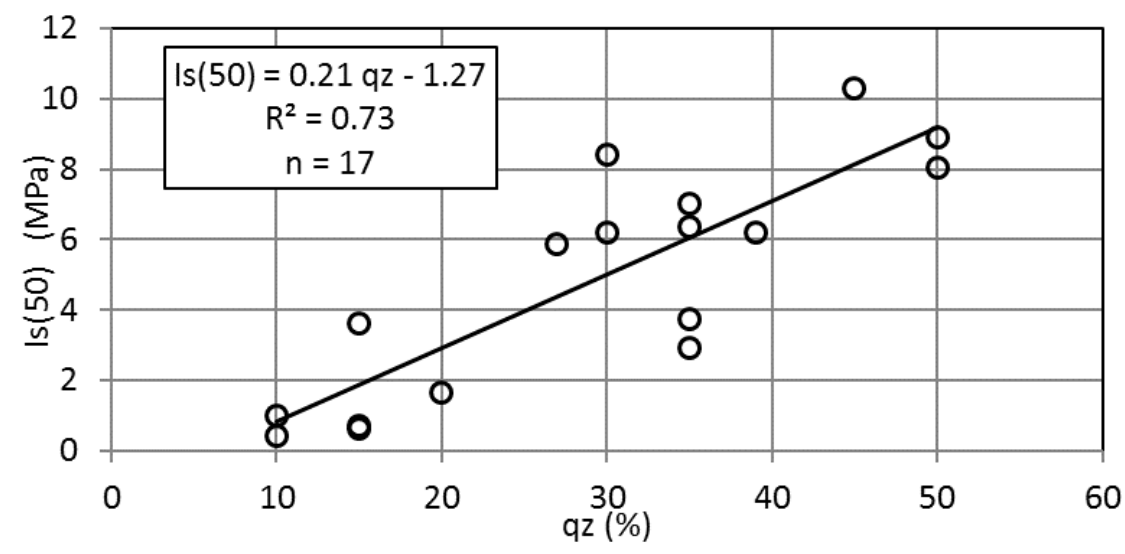

Figure 1 - Correlation between point loading strength $\left(I_{s(50)}\right)$ and quartz content $\left(q_{z}\right)$.

- $\quad$ Matrix content , $\mathrm{mtx}(\%)$ and point loading index $\mathrm{I}_{\mathrm{s}(50)}(\mathrm{MPa})$

The correlations between strength and cement or matrix percent were investigated by limited number of researchers. Generally, sandstones with higher matrix content tend to have higher strength than those of lower matrix content (Clough et al. 1981; David et al. 1998). In this study, these parameters are related conversely (Figure 2) and a linear decrease of strength with increasing matrix content is shown. The term "matrix" is often referred to the fine particles between the grains. These fine particles in fact include "matrix" deposited during sediment processes and "matrix" formed during diagenetic processes (cement). The bonding strength of the matrix depends on the cement content within it. In practice, it is difficult to distinguish the cement content within the fine particles especially when observing thin sections. So, the estimated inverse correlation may be due to the low cement content of the mixture of "matrix" that gives lower bonding strength to the total "matrix".

- $\quad$ Packing Density, $\mathrm{PD}(\%)$ and point loading index $\mathrm{I}_{\mathrm{s}(50)}(\mathrm{MPa})$

The packing density is a measure of grain packing arrangements and can be determined by thin section studies considering the descriptions proposed by( Kahn, 1956). In this study, the estimated values of PD are generally low $(<60 \%)$ due to high amount of matrix. A positive relation between PD and point loading strength is shown with an approximately linear function (Figure 3). (Ulusay et al. 1994) and (Zorlu et al., 2004) have also determined some moderate positive relationships.

- $\quad$ Grain Area Ratio (GAR) (\%) and point loading index $\mathrm{I}_{\mathrm{s}(50)}$ (MPa)

The majority of the tested sandstones have a rather small grain ratio (GAR $<50 \%)$, which indicates that more than a half of the area is filled with matrix material and porosity. In this study, these parameters are related proportional (Figure 4) and a linear increase of strength with increasing grain area ratio is shown. 


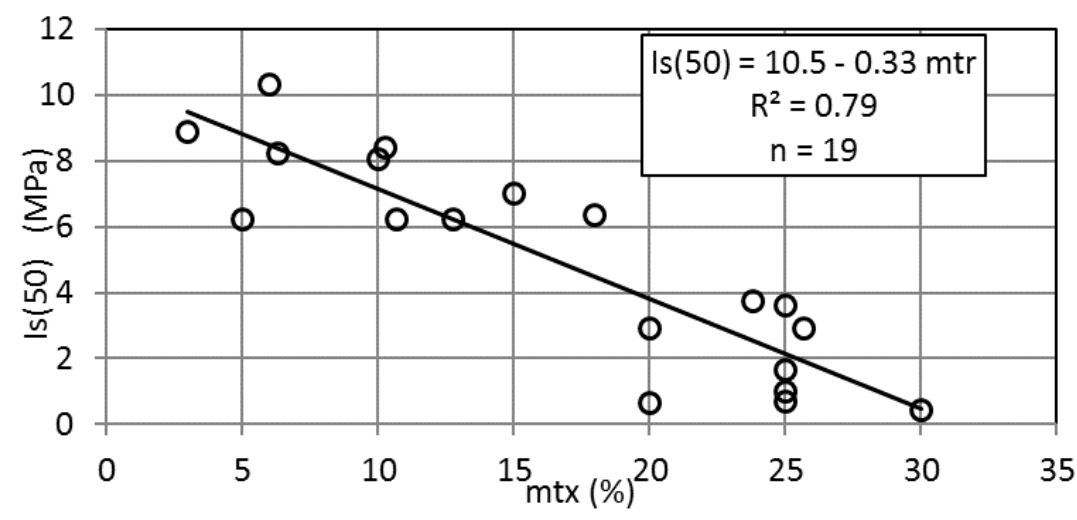

Figure 2 - Correlation between point loading strength $\left(I_{s(50)}\right)$ and matrix content $(\mathrm{mtx})$.

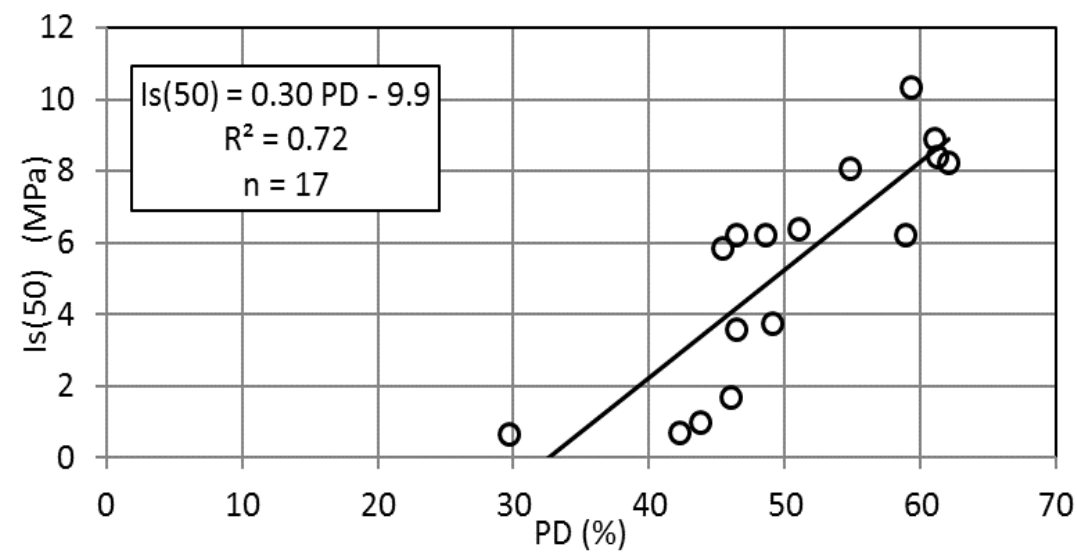

Figure 3 - Correlation between point loading strength $\left(I_{s(50)}\right)$ and packing density (PD).

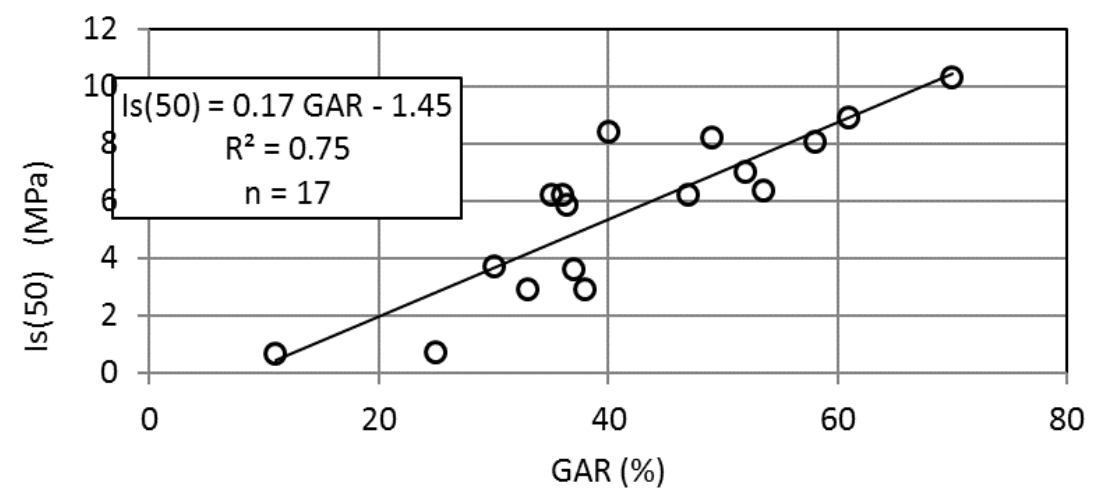

Figure 4 - Correlation between point loading strength $\left(I_{s(50)}\right)$ and grain area ratio (GAR).

\section{Conclusions}

Being the inherent attributes of rock, the petrographic characteristics are the constructive parameters which influence its strength. With the increasing percentage composition of quartz grains in sandstones the point loading strength is gradually increased having a linear variation. Contrary, increasing percentage of matrix content resulted to strength decrease. 
The textural characteristics (packing density and grain area ratio) also appear to be very important to the mechanical behavior of sandstone. They have a positive influence on the strength measures with a linear trend.

\section{References}

Bell F.G. 1978. The physical and mechanical properties of the Fell sandstones, Northumberland, England, Engineering Geology, 12, 11 - 29

Bieniawski Z.T., 1974a. Estimating the strength of rock materials. Jl. S., Afr. Inst. Min. Metall., 74 , No 8, 312-320.

Bieniawski Z.T. 1975. The point load test in geotechnical practice, Engng. Geology, 9, 1 - 11.

Clough G.W., Sitar N. and Bachus R.C. 1981. Cemented sands under static loading, Journal of Geotechnical Engineering Division, 107(6), 700 - 817.

David C., Menendez B. and Bernabe Y. 1998. The mechanical behaviour of synthetic sandstones with varying brittle cement content, International Journal of Rock Mechanics and Mining Sciences, 35(6), $759-770$.

Dobereiner L. and De Freitas M.H. 1986. Geotechnical properties of weak sandsones, Geotechnique, 36, 79 - 94.

Ersoy and Waller 1995. Textural characterization of rock Engineering Geology, 39, 123 - 136.

Hawkins A.B. and Olver J.A.G. 1986. Point load tests: correlation factor and contractual use. An example from the Corralian at Weymouth. In: Hawkins, A.B. (Ed), Site Investigation Practice: Accessing BS 5930, Geological Society, London, 269-271.

ISRM Suggested Methods 1985. Suggested method for determining point load strength, Int. J. Rock Mech. Min. Sci. and Geomech. Abstr., 22, $51-62$.

Kahn J.S. 1956. The analysis and distribution of the properties of packing in sand size sediments, Journal of Geology, 64, 385 - 395

Kahraman S. 2001. Evaluation of simple methods for assessing the uniaxial compressive strength of rock, International Journal of Rock Mechanics and Mining Sciences and Geomechanics, Abstracts 38, $981-994$.

Norbury D.R. 1986. The point load test. In: Hawkins, A.B. (Ed.), Site Investigation Practice: Accessing BS 5930, Geological Society, London, 325-329.

Pettijohn F.J., Potter P.E. and Siever R. 1987. Sand and sandstones, Springer Verlag, Berlin, 533p.

Romana M. 1999. Correlation between uniaxial compressive and point load (Franklin test) strengths for different rock classes, 9th ISRM Congress, Vol1, Balkema, Paris, 673 - 676.

Smart B.D., Rowlands N. and Isaak A.K. 1982. Progress towards establishing relationships between the mineralogy and physical properties of coal measures rocks, International Journal of Rock Mechanics and Mining Sciences and Geomechanics, Abstracts 19, 81 - 89.

Sabatakakis N., Koukis G., Tsiambaos G. and Papanakli S. 2008. Index properties and strength variation controlled by microstructure for sedimentary rocks, Engineering Geology, 97, 80 -90 .

Shakoor A. and Bonelli R.E. 1991. Relationships between petrographic characteristics, engineering index properties and mechanical properties of selected sandstone, Bulletin of the Association of Engineering Geologist, 28, 55 - 71.

Tsiambaos G. and Sabatakakis N. 2004. Considerations on strength of intact sedimentary rocks, Engineering Geology, 72, $261-273$.

Ulusay R., Tureli K. and Ider M.H. 1994. Prediction of engineering properties of selected litharenite sandstone from its petrographic characteristics using correlation and multivariate statistical techniques, Engineering Geology, 37, 135 - 157.

Wentworth C.K. 1922. A scale of grade and class terms for clastic sediments, The Journal of Geology, vol. 30, No 5, $377-392$.

Zorlu K., Ulusay R., Ocakoglu F., Gokceoglu C. and Sohmez H. 2004. Predicting intact rock properties of selected sandstones using petrographic thin - sections data, International Journal of Rock Mechanics and Mining Sciences, 41(1), 93 - 98.

$\underline{\text { XLVII, No } 3-1730}$ 